\title{
Chinese Clothing Brands Use Social Media to Frame Young Female's Attitudes Towards Body Image
}

\author{
Yunfeng $\mathrm{Li}^{1, \mathrm{a}}$ \\ ${ }^{1}$ Public Relations, College of Humanities, Donghua University, Shanghai, China \\ aetliyunfeng@163.com
}

\begin{abstract}
This study will focus on how a Chinese clothing brand posts on social media frame young people's attitudes toward body image. The researcher has observed how this frame has changed based on the difference between five years ago and now. This research combines text analysis and interviews. The results show that models in advertisements influence viewers' attitudes about their bodies and physical appearance. People who regularly watch social media are more likely to have this effect. Moreover, even at present, the selection of models and the content has been very different, people will still obey the traditional aesthetic.
\end{abstract}

Keywords: body image, social media, framing, advertisements, general aesthetic.

\section{INTRODUCTION}

With science and technology developing rapidly, social media is thriving. Almost every young people uses social media every day. Many brands seize the opportunity and use social media to reach viral marketing. They put much advertising on social media platforms. Among these brands, the clothing brand is a very representative one. Posts from these clothing brands have flooded social media. Since the audience has received these posts for a long time, changes happened regarding their body image attitude. In other words, clothing brands use social media to persuade and frame audiences. There are many clothing brands in China, so this research only selects one representative clothing brand. This brand is PEACE BIRD (women), a wellknown clothing brand in China. Almost every young woman in China knows or has bought its clothes. As a result, PEACE BIRD's posts on social media are typical among brands in China.

This article focuses on how Chinese clothing brands frame young females' attitudes toward body image on social media. This paper selects posts of different years and uses qualitative research. The researcher will analyze what kinds of posts make people feel more negative or positive about their bodies and the changing trend of the frame.

\section{LITERATURE REVIEW}

After looking up literature, the content on social media does serve as a frame for people. Advertising acts as a persuasive strategy, and companies often use advertisements to shape the audience's attitudes[1]. As for clothing brands, their advertisements will frame the audience's perceptions of appearance.

Researches proof that exposure to gorgeous pictures on social media, which includes images of tall and slim young ladies, can raise the possibility of body shame and appearance anxiety[2]. Scholars found that some TV programs showed the ideal body shape, such as films and TV series. Furthermore, there is a positive correlation between watching TV and body dissatisfaction[3]. When it comes to social media, the frame is even more vital. Social media can help social media get viral spread and expand the audience group[4]. A study carried out by Fardouly, Pinkus and Vartanian[5] shows that Facebook usage links to a more negative mindset among young women. These ladies are more likely to change their appearance, such as altering their hairstyles and making their skin sexier. These influences did not solely happen on long-term use but also affect people who only use Facebook briefly. Based on this case study, they point out that the posts on Facebook caused more dissatisfaction with skin, hair, and face, while the unpleased with body fat and thin was not significant[5]. Also, the fitness photos can dramatically predict the 
participants' weight-loss behaviors[6]. That means and the media always presents idealized bodies and delicate faces in front of the public. Then people would show more intensive will towards changing their bodies and appearance, which leads to anxiety and inferiority[7].

Beyond that, there is also a connection between framing theory and audience preference. If the audiences are interested in dissemination, the frame will be easier to present[4]. When it comes to the body display, the posts of clothing brands directly impact the audience. These brands also frame their audience attitudes towards appearance. Similar to metaphors in the news, advertising tries to guide the audience. Haristmawan's[8] article notes that words and pictures in the news often have cultural meanings behind them. Even though words can impress the audience, visual elements are more appealing to people. The brands' posts always try to persuade their audiences by delivering the lifestyles[9]. Through this way, they can convince the audience that the general aesthetic advocates are tall and slim. This aesthetic may push college girls to self-objection, followed by eating disorders, debilitating social interactions[10]. Thus, after viewing these images, young women would feel upset about their bodies. From a perspective about mood and framing, Martin and Lawson describe that passive advertising content will have a more significant impact on audiences than positive ones[11]. Scholars concluded that the passive information is more talented of framing, which can cause a "vicious circle".

Moreover, some research found that celebrity involvement positively correlates with women's dissatisfaction with their body images[12]. There is no shortage of celebrities on social media, and many brands use the well-known person in advertisements to display their products better and attract more exposure. The use of celebrities' images can connect products and famous people[13]. Many fashion and beauty bloggers post pictures of fitting clothes and makeup to show off their beautiful bodies. Several studies shed light on that these key opinion leaders are often used to help promote companies' products[14]. Nevertheless, not all people can get ideal bodies like the celebrities, even if they dress like the celebrities in the advertisements.

The theory of "Use and Gratification"[15] and the idea of "Social Comparison"[5] have explanatory value for framing. According to the "use and gratification" theory, many images shown on social media are idealized bodies, which most people cannot reach[15]. At the same time, communication and entertainment are two reasons for people use social media. In that case, these posts cannot meet people's needs, and netizens feel disappointed. Meanwhile, individuals have different levels of satisfaction on social media. Those who are easily distracted by news body shapes are less likely to be satisfied [16]. Then, talking about "Social
Comparison", social media can "cultivate" a sense of comparison[5]. Social media offers young women a vast platform for comparison. Thus, it is a space of interaction where people express themselves by posting images. Judgment about body and appearance happened more frequently[17]. People's awareness of social comparison increased during the process of browsing social media content. People are more likely to find their shortcomings by comparing. In that case, body shame has more opportunities to get in their mood. Therefore, scholars also found that social comparison has two directions: upward and downward. Johnson and Knobloch[18] proved that upward comparisons, though motivating, are more likely to trigger negative emotions. In contrast, downward comparisons can improve people's moods.

Nowadays, more feminist researchers are speaking out for eliminating body shaming. Some scholars and sociologists try to promote the broadening of aesthetic abilities and focusing on body positivity should be encouraged[19]. However, in China, the fight against body shaming has not been a widespread issue for a long time. This article would focus on Chinese clothing brands and observe how it frames people's attitudes toward appearance on social media. Nevertheless, the literature's main limitation is that they emphasized the adverse effects of body images on social media. However, in recent years, many companies have eliminated body shaming and appearance shaming from their advertising. Furthermore, expressing appreciation of different kinds of bodies is vital to finding these positive opinions and observing the changes of the frame.

\section{Method}

Hoping to study how Chinese women's clothing brands frame their audiences, the researcher will combine text analysis and interviews. This article contributes to finding out what kind of changes in the audience's attitudes towards the body shape after receiving the information released by these brands on social media. The questions will include demographic questions, their exposure to advertising, and questions about body image. Moreover, the chosen social media platform is Sina Weibo. Weibo, similar to Twitter, is one of China's most popular social media. As of December 2020, the average daily active users of Weibo were 225 million. The researcher can filter PEACE BIRD's posts get ones during a specific period. This study chose 2016 and 2021, from January to April. This research will divide the data into two groups for 2016 and 2021, and each group will contain six posts.

\subsection{Paticipant}

Since the audience of PEACE BIRD is mainly young women, the interview participants are also young 
women. They are between 18 and 25 years old and are all from a university in Shanghai. There were two groups, and each group includes four people. All of them are social media users, and they all use Weibo. Moreover, according to the preliminary investigation, none of these participants have evident mental diseases, such as depression and anorexia.

\subsection{Measure}

First of all, this study will analyze the content of the PEACE BIRD released on Weibo. The researcher wants to look for the descriptions of bodies and physical appearance in their advertisements' text. In that case, analyzing the value orientations of these words can be more accessible. Besides, the researcher will collect images and videos in the posts. Then, what kind of physical appearance the actors had is also essential. The study will also record and analyze the wording that the brand used.

We presented two groups of interviewees with posts from different years. Posts 2016 is full of slim, tall models. The international models that PEACE BIRD invited were all white people. In 2016, PEACE BIRD did not use videos. They just used pictures to show the clothes. When it comes to posts in 2021, models are of all shapes and sizes. The vast majority of these people are Chinese. In addition to using models or celebrities to show off clothes, PEACE BIRD adds value to the content. Such as, they produce video continually. The content of the video is storytelling, conveying the concept like "chasing freedom" and "being yourselves" by telling the models' own stories. Apart from the various models, there are also significant differences in wording. In 2016, there are plenty of references to phrases like "If you do not lose weight, you will feel sad when you show your body in the summer" and "Show off your slim waist". These words give viewers a psychological hint that thin bodies are beautiful and fat people should be ashamed. In the content of 2021, the wording is primarily positive, such as "be brave to be yourself", "external standards should not be a problem", "dress freedom", and so on. The text is in line with video and pictures. It will make the viewer feel comforted and persuaded.

Before the interview, the researcher will briefly introduce the background of the interview. Nevertheless, the participants will not directly know that the discussion is about body shame and appearance anxiety. Otherwise, participants would have psychological hints. These hints can affect the authenticity of their answers.

In the interview, the research would invite two groups of interviewees. The first group will read the posts of 2016, and the second group will watch the ones of 2021. In the following 15-20 minutes, participants will answer some questions. Interviewees will describe their appearance before viewing social media content. The researcher will compare the changes in the ratings given by the two groups. The items here refer to Pingitore and Garfieldt's[20] scale for measuring body satisfaction. The researcher will also ask participants whether they like these posts. According to the interviewees' answers, the researcher can analyze which words and images are attractive. Simultaneously, the researcher will ask whether the respondents would like to swap the body with the advertisement models[21], including the figure, clothes.

Moreover, the participants should answer whether they often compare the appearance with persons in advertisements. To prove whether social comparison theory[5] plays a role, the question also involves "Have you ever met the occasion that you find the differences between yourself and the mode when you try on the same clothes? How ?".

Subsequently, the interviewer will ask, "If a clothing brand invites you to be a model for a, would you be willing to go?". This question aims to find out if they felt confident about their appearance and body shape. In addition, to explore the changing current framework. The researcher will ask what body or physical appearance can become a model in clothing brands' posts. In this way, analyzing whether interviewees have stereotypes about attractive bodies can be more manageable.

Furthermore, this interview will include open-ended questions. The researcher can compare the differences between the answers from the two groups and predict their degree of body shame according to their willingness to answer questions about body image. When people were able to come up with many unpleasant examples of their bodies immediately, they may suffer from body anxiety.

\section{FINDINGS}

When it comes to what forms of advertising are more attractive, respondents said that what catches their attention most directly are the pictures. While in terms of content, they prefer the stories the videos convey. The interviewees did not leave a deep impression of the text and even ignored it directly. It is easier for people to receive visual information than reading and comprehension. Therefore, when brands use pictures, these colors and shapes will make consumers passively accept the message. However, the videos are richer in stories than pictures. Thus, when people have plenty of time to look at these posts, they will be much more impressed with the videos. In 2016, the frame forms were relatively simple, but in 2021, they add videos, which improve communication.

The interviewees who watch the advertisements in 2016, show more negative emotions on their bodies. When asked, "Have you ever met the occasion that you 
find the differences between yourself and the mode when you try on the same clothes?", they were able to talk two or three examples. Still, participants in "group 2021" mostly responded with only one example. A girl even said, "I will not feel sad cause I do not have to look like a model." "Group 2016" were able to describe their own experiences with body comparisons quickly, suggesting that the posts reminded them of unpleasant experiences in their daily lives. The posts in 2016 offer strong guidance to contrast appearance. In these comparisons, the audience will find their bodies are far from the models. In the frame of 2016, PEACE BIRD sent the idea of being "thin", "tall" and "light skin" as beauty. Under the influence of this frame, people will accept this aesthetic. However, there is a gap between audiences' bodies and this aesthetic. Thus, body shame took over their brain.

The participants who watched posts from 2021 showed more confidence in their bodies and more tolerant of different body sizes. In group 2016, when they answered the question "What qualities do you think that a model must have?", everyone mentioned that models should be "tall," "thin," and "have long legs." However, when the interviewer asked "group 2021" the same question, half of the young women said the body shapes of models could be various as long as they were confident and showed off the beauty of clothes. When confronted with "If a clothing brand invites you to be a model, would you be willing to go?", all the members of the "group 2021" were willing to go. However, two girls in the "group 2016" were not. They think they are too short or have a "fat belly". The researcher finds that members of "group 2021" felt more confident about their bodies since the models in the advertisements are all bravely showing their bodies even they have different body sizes. In the frame of 2021, PEACE BIRD calls on people to appreciate all kinds of bodies and show themselves bravely. Therefore, the interviewees who receive the frame of 2021 will unconsciously identify with this concept.

The researcher predicts from the interview results that young women are more likely to have body dissatisfaction when faced with advertisements full of models with beautiful bodies. According to social comparison theory[17], people experience negative emotions when comparing themselves with others who are superior to them. Most people are not as tall and slim as many fashion models, nor do they look as good as the celebrities in the advertisements. Such upward comparison makes the audience more aware of their shortcomings, resulting in body shame[14]. Nevertheless, when they saw that the persons in the advertisement are ordinary-looking, such as having a slightly plump body and a freckled face. Participants will feel that this social comparison is insignificant. If they think they are more pretty than the model, this downward comparison will make them more confident. From the perspective of the "use and gratification theory"[15], netizens will feel dissatisfied when they find that their appearance does not conform to the criteria according to the aesthetics of the advertisements.

Beyond that, although the concept of "appreciating all shapes" and "dressing freedom" has been added to the frame. However, when respondents answered, "If you could make a wish and swap bodies with the person in the ads, would you swap?" and "What qualities do you think that a model must have? ", their aesthetic preference was still "tall" and "thin". The researcher believes that the long-term traditional aesthetic cognition needs a long time to change. Because just a few years ago, almost all advertising models had similar good bodies, so the frame has become so ingrained in everyone's mind that it will take years or even decades to change. Thus, the previous frame has profoundly shaped people's cognition of beautiful body image. Even if the frame has changed, people still need time to adjust their perceptions.

\section{CONCLUSION}

This study does have some limitations. The participants are all college students with an aboveaverage educational level in China. Which means they may have more rational feedback on social media content. Education, which may influence young women's outlook and values, may contribute to differences in response to these ads, but this study won't discuss.

Overall, this article argues that the posts that clothing brands post on social media will affect young women's attitude towards body image. Respondents who read posts from different years couldn't help but think in different frames. In these frames, viewers pay more attention to videos and pictures than to text content. Furthermore, the psychological comparison makes sense. Respondents would unconsciously compare themselves to the people in the advertisements. If they find the persons in the advertisements all have slim figures, audiences will feel less confident about their bodies. However, when they see models' body sizes are similar to theirs, users feel more empathy and not be ashamed. In a frame that promotes being tall and thin, people are more likely to be dissatisfied with their bodies. When facing the frame that shows multiple looks, people can accept their beauty more easily.

Fortunately, the social culture in China has also been progressing. Public opinion showing more tolerance and respect for body image. Clothing brands are also trying to educate consumers about the diversity of looks in their campaigns. Many young women already have a sense of not defining their bodies and expressing themselves with confidence. For example, the girls in the first group were all happy to pose for photos and videos. Despite the use of positive imagery and various 
models by many clothing brands, the general aesthetic still solid. The preferences for "light skin," "thin," and "tall" would keep a dominant position for a long time.

\section{REFERENCES}

[1] Christopher, A. A. (2013). Rhetorical strategies in advertising: The rise and fall pattern. Academic Journal of Interdisciplinary Studies, 2(8), 773.

[2] Monro, F., \& Huon, G. (2005). Media - portrayed idealized images, body shame, and appearance anxiety. International Journal of Eating Disorders, 38(1), 85-90.

[3] Tiggemann, M., \& Pickering, A. S. (1996). Role of television in adolescent women's body dissatisfaction and drive for thinness. International Journal of Eating Disorders, 20(2), 199-203.

[4] De Vreese, C. H. (2005). News framing: Theory and typology. Information design journal \& document design, 13(1).

[5] Fardouly, J., Pinkus, R. T., \& Vartanian, L. R. (2017). The impact of appearance comparisons made through social media, traditional media, and in person in women's everyday lives. Body image, 20, 31-39.

[6] Lewallen, J., \& Behm-Morawitz, E. (2016). Pinterest or thinterest?: Social comparison and body image on social media. Social Media+ Society, 2(1), 2056305116640559.

[7] Monro, F., \& Huon, G. (2005). Media - portrayed idealized images, body shame, and appearance anxiety. International Journal of Eating Disorders, 38(1), 85-90.

[8] Haristmawan, I. (2013). A Discourse Analysis Of Newspaper Leads In The Jakarta Post Using Frame Theory (Doctoral dissertation, Universitas Muhammadiyah Surakarta).

[9] Smith, V. (2008). Visual Persuasion: Issues in the translation of the visual in advertising. Meta: Journal des Traducteurs/Meta: Translators' Journal, 53(1), 44-61.

[10] Schmidt, C. K., Raque - Bogdan, T. L., \& Hollern, E. A. (2019). Self - Compassion, Affect, and Body Image in College Women. Journal of College Counseling, 22(2), 152-163.

[11] Martin, B., \& Lawson, R. (1998). Mood and framing effects in advertising. Australasian Marketing Journal (AMJ), 6(1), 35-50.
[12] Ho, S. S., Lee, E. W., \& Liao, Y. (2016). Social network sites, friends, and celebrities: The roles of social comparison and celebrity involvement in adolescents' body image dissatisfaction. Social Media+ Society, 2(3), 2056305116664216

[13] Darwish, A. S. (2015). Identification and Visual Rhetoric in Modern Advertisement Theory. Academic Journal of Interdisciplinary Studies, 4(3), 11.

[14] Van de Ven, N. (2017). Envy and admiration: Emotion and motivation following upward social comparison. Cognition and Emotion, 31(1), 193 200

[15] Whiting, A., \& Williams, D. (2013). Why people use social media: a uses and gratifications approach. Qualitative Market Research: An International Journal.

[16] Perloff, R. M. (2014). Social media effects on young women's body image concerns: Theoretical perspectives and an agenda for research. Sex Roles, 71(11-12), 363-377.

[17] Alperstein, N. (2015). Social comparison of idealized female images and the curation of self on Pinterest. The Journal of Social Media in Society, 4(2).

[18] Johnson, B. K., \& Knobloch-Westerwick, S. (2014). Glancing up or down: Mood management and selective social comparisons on social networking sites. Computers in Human Behavior, 41, 33-39.

[19] Leboeuf, C. (2019). What Is Body Positivity? The Path from Shame to Pride. Philosophical Topics, 47(2), 113-128. doi:10.2307/26948109

[20] Pingitore, R., Spring, B., \& Garfieldt, D. (1997). Gender differences in body satisfaction. Obesity research, 5(5), 402-409.

[21] Dohnt, H., \& Tiggemann, M. (2006). The contribution of peer and media influences to the development of body satisfaction and self-esteem in young girls: A prospective study. Developmental psychology, 42(5), 929 